\title{
Chronic primary hyperinsulinaemia is associated with altered insulin receptor $m R N A$ splicing in muscle of patients with insulinoma
}

\author{
P. Sbraccia ${ }^{1,2}$, M. D'Adamo ${ }^{1}$, F. Leonetti ${ }^{1}$, S. Caiola ${ }^{2}$, P. Iozzo $^{1}$, A. Giaccari ${ }^{1,2}$, A. Buongiorno' ${ }^{2}$, G. Tamburrano ${ }^{1}$ \\ ${ }^{1}$ Division of Endocrinology 1, Università "La Sapienza", Rome, Italy \\ ${ }^{2}$ Clinical Biochemistry Laboratory, Istituto Superiore di Sanità, Rome, Italy
}

Summary Alternative splicing of the 36-base pair exon 11 of the human insulin receptor gene results in the synthesis of two insulin receptor isoforms with distinct functional characteristics (the isoform containing exon 11 has lower insulin binding affinity and lower internalization rate). Altered expression of these insulin receptor isoforms has been previously demonstrated in skeletal muscle of patients with non-insulin-dependent diabetes mellitus (NIDDM). However, this observation was not confirmed by other studies and is still a matter of controversy; furthermore, it is not known whether it represents a primary event or is secondary to hyperinsulinaemia and insulin resistance. In order to address this issue in patients with pure non-genetically determined hyperinsulinaemia, we examined the alternative splicing of insulin receptor mRNAs in skeletal muscle of eight patients with surgically confirmed insulinoma and insulin resistance and in eight healthy subjects, using the reverse transcriptase-polymerase chain reaction technique. The insulinoma patients displayed a significant increase in the expression of the insulin receptor isoform containing exon $11(75.7 \pm 2.3 \%)$ when compared with normal subjects $(57.9 \pm 1.5 \%)$; furthermore, this increase was positively correlated with plasma insulin concentration and negatively correlated with in vivo insulin sensitivity (glucose clamp). In conclusion, the increased expression of the insulin receptor isoform with lower insulin binding affinity in patients with primary non-genetically determined hyperinsulinaemia supports a role for insulin in the regulation of alternative splicing of insulin receptor pre-mRNA and suggests that in NIDDM an altered receptor isoform distribution might be secondary to the ambient hyperinsulinaemia rather than representing a primary defect. [Diabetologia (1996) 39: 220-225]

Key words Insulin receptor, alternative splicing, hyperinsulinism, insulin resistance, insulinoma.
The human insulin receptor gene is located on the short arm of chromosome 19 and consists of 22 exons spanning more than 120 kilobase pairs [1]. It encodes an $\alpha 2 \beta 2$ disulphide-linked tetrameric glycoprotein located in the plasma membrane of target cells [2-5], that exists in two isoforms generated by tissue-specific alternative splicing of the 36-base pair exon 11

Received: 5 April 1995 and in revised form: 14 July 1995

Corresponding author: Dr. P. Sbraccia, Cattedra di Endocrinologia 1, Clinica Medica 2, Policlinico Umberto I, Viale del Policlinico, I-00161 Roma, Italy

Abbreviations: RT-PCR, Reverse transcriptase-polymerase chain reaction technique; NIDDM, non-insulin-dependent diabetes mellitus; bp, base pair.
[6-9]. As a result, the encoded receptor isoforms either contain (isoform Ex11 + or B) or lack (isoform Ex11- or A) a 12-amino acid sequence at the carboxy-terminus of the $\alpha$-subunit. This structural difference leads to distinct functional characteristics: the shorter Ex11- isoform has an approximately twotimes higher insulin binding affinity $[8,10,11]$, increased internalization rate $[10,12]$, and, consequently, an increased sensitivity to insulin for some of the biological actions $[8,10,11]$. Therefore, it is possible that insulin receptor mRNA alternative splicing represents a regulatory mechanism for rapid switching in isoform expression and modulation of insulin sensitivity, and that an altered relative expression of these receptor isoforms, especially in skeletal 
muscle, may contribute to the development of insulin resistance. In this regard, it has been recently demonstrated, both at the mRNA and the protein levels, that skeletal muscle [13-15] and adipocytes [16] of patients with non-insulin-dependent diabetes mellitus (NIDDM) express increased amounts of the Ex11 + isoforms compared with non-diabetic control subjects; similar results have also been obtained in prediabetic insulin-resistant individuals [17]. These observations, however, were not confirmed by other studies $[9,18,19]$ and are still a matter of controversy. Possible reasons for these discrepancies include differences in experimental methods, site of tissue biopsies, control groups, and perhaps more importantly, differences in the metabolic status of diabetic patients. In fact, it is not known whether hyperinsulinaemia itself could have a role in the alternative splicing of the insulin receptor pre-mRNA. In order to address this specific issue our study aimed at determining whether pure non-genetically-induced hyperinsulinaemia in patients with insulinoma is associated with an alteration of the relative expression of the two insulin receptor $m R N A$ isoforms.

\section{Subjects, materials and methods}

Insulin infused during clamp studies (Humulin R) was purchased from Eli Lilly (Indianapolis, Ind., USA); M-MLV reverse transcriptase was purchased from GIBCO-BRL (Gaithersburg, Md., USA) and random hexamer primers from Pharmacia (Uppsala, Sweden); Taq DNA polymerase (AmpliTaq) and dNTPs were obtained from Perkin-Elmer Cetus (Norwalk, Conn., USA). All other reagents were from Sigma (St. Louis, Mo., USA). Transfected NIH3T3 cells over-expressing the human insulin receptor without exon 11 (3T3-HIR-A) were kindly provided by Dr. A. Ullrich (Max Planck Institut für Biochemie, Martinsried, Germany); transfected NIH3T3 cells over-expressing the human insulin receptor with exon 11 (3T3-HIR-B) were kindly provided by Dr. J. Whittaker (State University of New York, Stonybrook, N.Y., USA). Human placenta, obtained during a cesarean section performed on a normal subject, was kindly provided by Dr. F. Fallucca (Università "La Sapienza", Rome, Italy).

Subjects. Eight patients with surgically proven insulinoma located within the pancreas were compared with eight sex- and age-matched control subjects with normal oral glucose tolerance and with no family history of NIDDM. The clinical characteristics of the subjects studied are presented in Table 1. None of the subjects were taking any medications known to alter carbohydrate metabolism. Abdominal wall muscle biopsies were obtained during either tumour removal in insulinoma patients or elective abdominal surgery (cholecystectomy for gallstones) in control subjects. In both groups, fasting plasma glucose and insulin concentrations were measured either at 08.00 hours on 4 different days during the 2 weeks preceding surgery (averages of these values are indicated in Table 1) or at the time of muscle biopsy. Informed consent was obtained from all subjects after explanation of the procedure and the study was approved by the local ethical committee and was performed in accordance with the principles of the Helsinki Declaration.
Table 1. Clinical and metabolic characteristics of study population

\begin{tabular}{|c|c|c|}
\hline & $\begin{array}{l}\text { Insulinoma } \\
\text { patients }\end{array}$ & $\begin{array}{l}\text { Control } \\
\text { subjects }\end{array}$ \\
\hline \multicolumn{3}{|l|}{ Clinical data } \\
\hline$n$ & 8 & 8 \\
\hline Age (years) & $44.6 \pm 6.2$ & $46.3 \pm 5.4$ \\
\hline Sex (female/male) & $4 / 4$ & $5 / 3$ \\
\hline Disease duration (months) & $19 \pm 4$ & - \\
\hline Body mass index $\left(\mathrm{kg} / \mathrm{m}^{2}\right)$ & $25.5 \pm 1.2$ & $23.8 \pm 1.5$ \\
\hline \multicolumn{3}{|l|}{ Metabolic and clamp data } \\
\hline $\begin{array}{l}\text { Fasting plasma glucose } \mathrm{e}^{\mathrm{a}} \\
(\mathrm{mmol} / \mathrm{l})\end{array}$ & $2.52 \pm 0.1^{b}$ & $4.55 \pm 0.4$ \\
\hline $\begin{array}{l}\text { Fasting plasma insulin }{ }^{\mathrm{a}} \\
\text { (pmol/l) }\end{array}$ & $322.9 \pm 39.0^{\mathrm{b}}$ & $48.5 \pm 3.6$ \\
\hline $\begin{array}{l}\text { Steady-state plasma insulin } \\
\text { (pmol/l) }\end{array}$ & $925.6 \pm 129.2$ & $710.3 \pm 107.6$ \\
\hline $\begin{array}{l}\text { Glucose uptake } \\
\left(\mu \mathrm{mol} \cdot \mathrm{kg}^{-1} \cdot \mathrm{min}^{-1}\right)\end{array}$ & $19.6 \pm 2.8^{\mathrm{b}}$ & $40.9 \pm 0.4$ \\
\hline \multicolumn{3}{|c|}{ Metabolic data prior to muscle biopsy } \\
\hline $\begin{array}{l}\text { Fasting plasma glucose } \\
\text { (mmol/l) } \\
\text { Fasting plasma insulin } \\
\text { (pmol/l) }\end{array}$ & $\begin{array}{l}2.8 \pm 0.8^{b} \\
328.7 \pm 41.3^{b}\end{array}$ & $49.3 \pm 4.4$ \\
\hline
\end{tabular}

Values are mean \pm SEM. ${ }^{a}$ Mean of measurements carried out on 4 different days during the 2 weeks preceding surgery; b $2 p<0.001$ vs control subjects

In vivo assessment of insulin action. Insulin-mediated wholebody glucose utilization was determined by the euglycaemic hyperinsulinaemic clamp technique, as previously described [20], no longer than 3 weeks before surgery. Studies were started at 08.00 hours after a 10 -h overnight fast. Euglycaemia was slowly reached in patients with insulinoma with a constant glucose infusion at a rate of $10 \mu \mathrm{mol} \cdot \mathrm{kg}^{-1} \cdot \mathrm{min}^{-1}$; insulin was then constantly infused at a rate of $1.0 \mathrm{mU} \cdot \mathrm{kg}^{-1} \cdot \mathrm{min}^{-1}$ for $2 \mathrm{~h}$ after $10 \mathrm{~min}$ of priming $(30 \mathrm{mU} / \mathrm{kg})$. Euglycaemia was maintained by a variable glucose infusion using the negative feedback principle. Rates of insulin-mediated glucose uptake were calculated on the basis of glucose infusion rates during the last $60 \mathrm{~min}$ of the clamp, when steady-state was reached. Plasma glucose was measured by the glucose oxidase method (Glucose Analyzer II; Beckman Instruments, Inc., Palo Alto, Calif., USA) and plasma insulin by double-antibody radioimmunoassay (Pharmacia Diagnostics AB, Uppsala, Sweden).

Muscle biopsy. All subjects underwent surgery after an overnight fast. General anaesthesia was induced with a short-acting barbiturate and maintained by phentanyl and nitrous oxideoxygen mixture. Only $150 \mathrm{mmol} / 1 \mathrm{NaCl}$ was given i.v., and blood samples for determination of plasma glucose and plasma insulin concentrations were drawn before the muscle biopsy. Immediately after exploring the abdomen, $0.5-1 \mathrm{~g}$ of abdominal wall muscle was removed through the incision. The muscle specimens were immediately freeze-clamped between aluminum tongs pre-cooled in liquid nitrogen and then stored at $-80^{\circ} \mathrm{C}$ prior to $\mathrm{RNA}$ preparation.

$R N A$ preparation. Skeletal muscle specimens $(-200 \mathrm{mg})$ were pulverized in liquid nitrogen. Poly $(\mathrm{A})^{+}$RNA was isolated using Micro-Fast Track mRNA isolation kit (Invitrogen, San Diego, Calif., USA) according to the manufacturer's protocol.

cDNA synthesis and PCR amplification. First strand cDNA synthesis was performed on 2-4 $\mu$ g of Poly(A) ${ }^{+}$RNA using 
M-MLV reverse transcriptase and random hexamer primers in a total volume of $20 \mu \mathrm{l}$ of (in mmol/l) $50 \mathrm{KCl}, 10 \mathrm{Tris} \mathrm{HCl} \mathrm{pH}$ $8.3,5 \mathrm{MgCl}, 1$ deoxynucleotide triphosphates.

The entire 20- $\mu \mathrm{l}$ cDNA synthesis reaction volume was combined in a $100-\mu l$ final reaction volume for PCR amplification containing $0.2 \mu \mathrm{mol} / 1$ of oligonucleotide primers spanning nucleotides 2229-2250 (5'-AACCAGAGTGAGTATGAGGAT-3') and 2844-2865 (5'-CCGTTCCAGAGCGAAGTGCTT-3') [6] of the human insulin receptor sequence (numbering according to Ebina et al. [21]) and 2.5 U Taq DNA polymerase. PCR amplification was carried out for 25 cycles of $20 \mathrm{~s}$ at $96^{\circ} \mathrm{C}, 30 \mathrm{~s}$ at $58^{\circ} \mathrm{C}$, and $1.5 \mathrm{~min}$ at $72^{\circ} \mathrm{C}$, using a DNA thermal cycler (Perkin-Elmer Cetus). The authenticity of the PCR products was confirmed by Southern blot analysis with a human insulin receptor cDNA probe. Products of PCR amplification were resolved by electrophoresis on $20 \%$ polyacrilamide gels. Gels were silver-stained and band density quantified by laser scanning densitometry (Hoefer, San Francisco, Calif., USA). Alternatively spliced insulin receptor mRNA transcripts were measured twice in each muscle sample.

Furthermore, to estimate the reproducibility of the method, messenger RNA was isolated from one muscle and divided into six aliquots, with subsequent RT-PCR amplification; ten different experiments, starting from the same muscle, were also performed to test between-run variability. The quantification of the PCR products, carried out as described above, revealed a coefficient of variation of 2.6 and $4.8 \%$ intra- and inter-assay, respectively.

\section{Statistical analysis}

Results are presented as mean \pm SEM. Differences between groups were assessed using the Student's $t$-test for unpaired data.

\section{Results}

Insulin-mediated glucose uptake rates were significantly lower in patients with insulinoma when compared with control subjects $(19.6 \pm 2.8$ vs $40.9 \pm$ $0.4 \mu \mathrm{mol} \cdot \mathrm{kg}^{-1} \cdot \mathrm{min}^{-1}, 2 p<0.001$, Table 1$)$. By definition, insulinoma patients were significantly hyperinsulinaemic and hypoglycaemic (Table 1). In both groups, fasting plasma glucose and insulin concentrations measured immediately before the muscle biopsy were almost superimposable on the mean plasma values obtained by different determinations performed on the days before surgery (Table 1).

In order to validate our RT-PCR assay, mRNA was extracted from transfected $3 \mathrm{~T} 3$ cell lines expressing either the Ex11 + or the Ex11- insulin receptor splice variant. The two mRNA variants were mixed at varying known ratios, and cDNA synthesis and PCR coamplification were carried out using oligonucleotide primers flanking the Exon 11 splice site. The PCR product ratios were almost identical to the initial mRNA ratios $\left(r=0.99 ; p<10^{-6} ;\right.$ Fig. 1$)$.

The electrophoretic analysis of the fragments representing isoforms Ex11 + (636 bp) and Ex11- (600 bp), obtained by PCR amplification of the cDNA de-

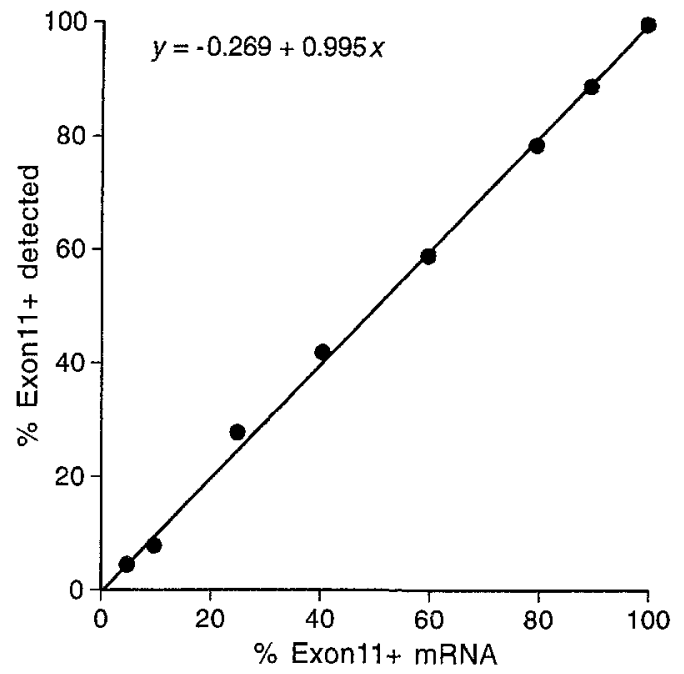

Fig. 1. Validation of RT-PCR assay. The mRNA was isolated from 3T3-IR-A and 3T3-IR-beta-cell lines expressing either the Ex11- or the Ex11 + insulin receptor splice variant, respectively. The two mRNA variants were mixed at varying known ratios ( $x$-axis), and RT-PCR co-amplified using oligonucleotide primers flanking the Exon 11 splice site. After electrophoresis and silver-staining, band densities were quantified by laser scanning densitometry, and the percent Ex $11+$ mRNA variants were calculated ( $y$ axis). $p<10^{-6}, r=0.999$

rived from skeletal muscle mRNAs of both groups, using oligonucleotide primers flanking the Exon 11 splice site of the human insulin receptor sequence, is shown in Figure 2A. Both insulin receptor isoforms were present in all subjects studied, but the ratio between Ex11 + and Ex11- isoform was higher in patients with insulinoma when compared with control subjects. After band densitometric analysis the relative amount of the Ex11+mRNA splicing variant was calculated and expressed as percent of total $($ Ex11 + plus Ex11-) in Figure 2B. The mean value of the relative percent Ex11 + isoform expression in patients with insulinoma, shown in Figure $2 \mathrm{C}$, was significantly higher when compared with control subjects $(75.7 \pm 2.3 \%$ in insulinoma patients vs $57.9 \pm 1.5 \%$ in control subjects; $p<0.01$ ).

Subsequently, in order to estimate whether a correlation existed between interindividual variations of insulin receptor Ex11 + mRNA relative expression and fasting plasma insulin concentrations in patients with insulinoma, we performed linear regression analysis. The results, shown in Figure 3A, demonstrate that the percentages of Ex11 + relative expression are positively correlated with fasting plasma insulin concentrations, and, although the sample group is small, the correlation coefficient of 0.93 enabled us to consider the data to be highly significant $(p<0.001)$. Furthermore, since in insulinoma patients insulin resistance develops as a consequence of increased insulin secretion, we also attempted to find a correlation between unspliced insulin receptor 


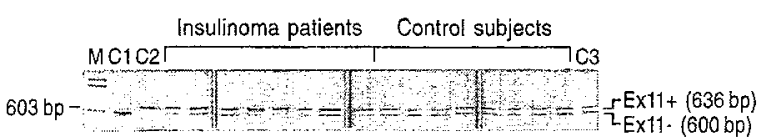

A
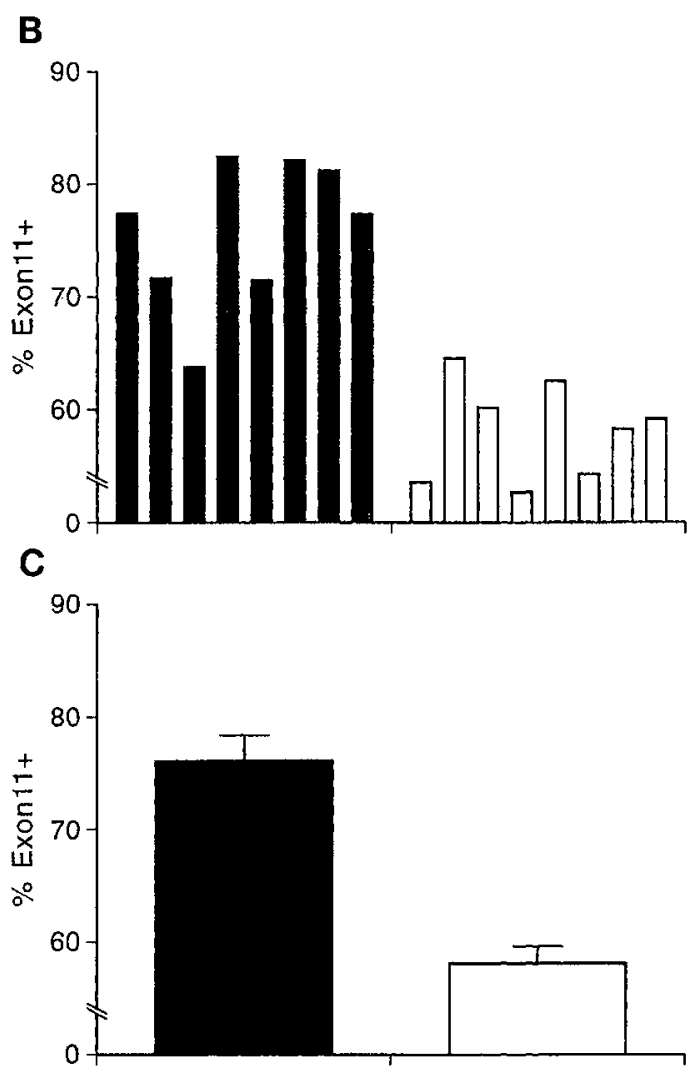

Fig. 2A-C. RT-PCR amplification of alternatively spliced insulin receptor mRNA transcripts (see Methods) in skeletal muscle of insulinoma patients and control subjects. A Silverstained non-denaturing $20 \%$ polyacrilamide gel showing the 600 and 636 bp DNA fragments generated by PCR amplification of the two (Ex11 + and Ex11-) insulin receptor cDNA species. PCR-products derived from mRNA of transfected 3 T3 cells expressing either the Ex11- (C1) or the Ex11 + (C2) insulin receptor splice variant and from human placenta (C3) (that expresses both mRNA variants equally) were also included as controls. HaeIII-digested $\Phi$ X174 DNA molecular size markers are shown in the far left lane. B Ex11 + mRNA variant expressed as percent of total $(\mathrm{Ex} 11+$ plus Ex11-). C Mean values of relative percent $E x 11+m R N A$ variant in both groups: insulinoma patients ( $\square$ ) and control subjects $(\square)$

mRNA relative expression and insulin-mediated glucose uptake, as shown in Figure 3B. This correlation existed and was, as expected, negative $(r=-0.95$, $p<0.001)$. The Ex11 + relative expression was also positively, although not significantly, correlated with body mass index; whereas it did not correlate with age, fasting plasma glucose concentrations, and duration of disease (data not shown).
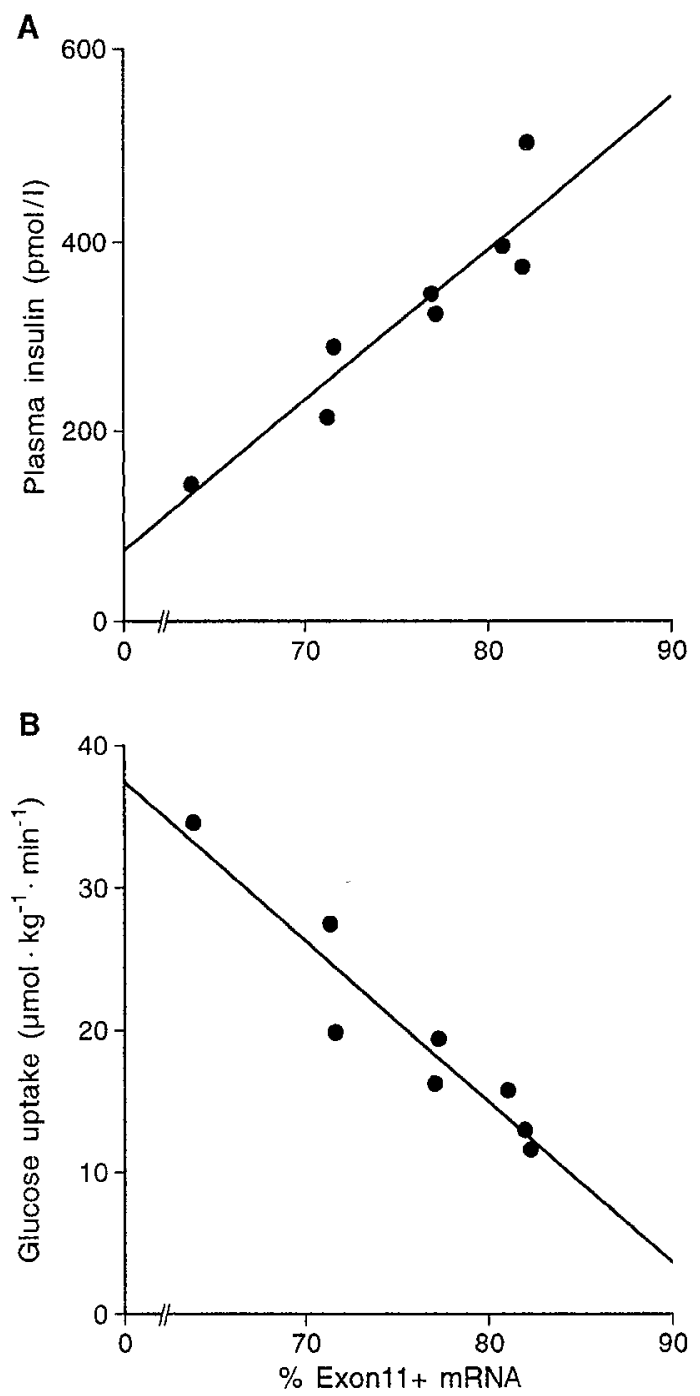

Fig.3A, B. Relative percent Ex11 + skeletal muscle mRNA variant of insulinoma patients in relation to plasma insulin concentrations $(r=0.93 ; p<0.001 ; \mathbf{A})$ and insulin-mediated glucose uptake rates during euglycaemic clamps $(\mathbf{B})(r=-0.95$; $p<0.001)$

\section{Discussion}

In the present study we examined the role of chronic hyperinsulinaemia due to an insulin-secreting tumour, in the skeletal muscle mRNA expression of the two insulin receptor isoforms. One of the major challenges in unravelling the molecular defects that lead to insulin resistance, a well-documented physiopathological abnormality in NIDDM, is the need to distinguish between primary vs secondary events. However, in patients with impaired glucose tolerance or NIDDM it is difficult to evaluate whether a given defect in the insulin action pathway precedes or follows the hyperinsulinaemic response to insulin resistance. Patients with insulinoma therefore represent a unique opportunity to investigate the effect of longterm hyperinsulinaemia independent of underlying insulin resistance. 
In the present study we demonstrate that chronic hyperinsulinaemia is associated with a higher relative expression of the skeletal muscle insulin receptor isoform with lower binding affinity. This result may provide a key to interpretation of the discordant data reported by different groups who have examined receptor isoform distribution in diabetic patients [13-19]. In these reports, the metabolic status of the patients studied ranged from glucose intolerance to overt diabetes; and since this progression is usually paralleled by the decline of plasma insulin concentrations which accompany increases in glycaemia, the differences in receptor isoform distribution between insulin-sensitive and overt diabetic patients may have been minimal or absent due to similar plasma insulin levels. In support of our findings, enhanced relative expression of Ex11 + mRNA isoform has been recently reported in FAO rat hepatoma cells after incubation with insulin [22]. This finding may also explain why the liver, which is exposed to portal insulin concentrations two- to three times higher than in the peripheral circulation, expresses almost exclusively the Ex11 + isoform [6-8]. Furthermore, previous studies also revealed that initiation of insulin treatment in a diabetic patient with poor metabolic control was followed by an increase of the Ex11 + /Ex11- mRNA isoform ratio in skeletal muscle [23]. A similar link between hyperinsulinaemia and alteration in insulin receptor mRNA splicing was also reported in earlydiabetic rhesus monkeys [24]; in these animals, however, high plasma insulin levels were associated with decreased Ex11+ isoform expression. Inter-species variations probably account for this contradictory result.

Taken together, these data suggest that insulin may regulate its own receptor differential isoform expression. Our current data in insulinoma patients further support this hypothesis by also demonstrating a positive correlation between relative Ex11 + expression and plasma insulin concentrations; in fact, although correlation expresses only association, the fact that hyperinsulinaemia is the initial metabolic defect in patients with insulinoma strongly suggests causality. Thus, it is possible that in insulin-resistant prediabetic or early NIDDM patients alterations of the relative insulin receptor isoform distribution occur as a consequence of the compensatory hyperinsulinaemia; however, when beta-cell function deteriorates and more severe hyperglycaemia ensues, the alternate mRNA splicing defect is reversed. In this regard, we recently reported that $90 \%$-pancreatectomized diabetic rats show a normal pattern of receptor isoform distribution in both skeletal muscle and liver [25], suggesting that glycaemia is devoid of any regulatory effect.

We $[26,27]$ as well as others [28] have previously reported that insulinoma patients are insulin resistant; in the present study we confirm this finding and correlate the impaired insulin action with the preferential expression in skeletal muscle of the Ex11 + receptor isoform. This finding suggests, therefore, that in patients with insulinoma a predominant expression of the receptor isoform with lower affinity for insulin might be involved in the development of insulin resistance, in association with an overall reduction of surface receptors [29], and probably with a desensitization of tyrosine kinase activity [30].

In the present study we focused on the analysis of the two insulin receptor isoforms' expression at the mRNA level. We followed this approach for two reasons. First, measurement of the relative expression of insulin receptor isoforms at the protein level is complicated due to the possible hybrid formation between Ex11 + and Ex11- dimers. Second, it has been shown that the relative amounts of the two receptor isoforms expressed at the cell surface parallel their respective mRNA levels $[9,14]$.

In conclusion, our data provide evidence linking primary hyperinsulinaemia to alterations in insulin receptor mRNA isoform expression, and therefore support a role for insulin in the regulation of alternative splicing of insulin receptor pre-mRNA; moreover, this finding suggests that the altered receptor isoform distribution in NIDDM patients, rather than representing a primary defect might be due to the ambient hyperinsulinaemia.

Acknowledgements. This work was supported in part by the Eli Lilly/EASD Research Fellowship in Diabetes and Metabolism, and the Fondazione Istituto Pasteur - Fondazione Cenci Bolognetti of the University of Rome (to P. S.); by a fellowship (file 393323) from the Juvenile Diabetes Foundation (to A. G.); by the Centro Internazionale Studi Diabete (to G. T.); and by the Istituto Superiore di Sanità, Progetto Sindromi Ipoglicemiche, \#4.5 (to A. B.). We are grateful to E. Maroccia, D. Zorretta and G. Ricciardi from the Istituto Superiore di Sanità for their technical assistance.

\section{References}

1. Seino S, Seino M, Nishi S, Bell GI (1989) Structure of the human insulin receptor gene and characterization of its promoter. Proc Natl Acad Sci USA 86: 114-118

2. Goldfine ID (1987) The insulin receptor: molecular biology and transmembrane signaling. Endocr Rev 8: 235-255

3. Kahn CR, White MF (1988) The insulin receptor and the molecular mechanisms of insulin action. I Clin Invest 82 : 1151-1156

4. Olefsky JM (1990) The insulin receptor: a multifunctional protein. Diabetes 39: 1009-1016

5. Häring HU (1991) The insulin receptor: signalling mechanism and contribution to the pathogenesis of insulin resistance. Diabetologia 34: 848-861

6. Seino S, Bell GI (1989) Alternative splicing of human insulin receptor messenger RNA. Biochem Biophys Res Commun 159: 312-316

7. Moller DE, Yokota A, Caro JF, Flier JS (1989) Tissue-specific expression of two alternatively spliced insulin receptor mRNAs in man. Mol Endocrinol 3: 1263-1269 
8. Mosthaf L, Grako K, Dull TJ, Coussens L, Ullrich A, McClain DA (1990) Functionally distinct insulin receptors generated by tissue-specific alternative splicing. EMBO J 9: 2409-2413

9. Benecke H, Flier JS, Moller DE (1992) Alternatively spliced variants of the insulin receptor protein, expression in normal and diabetic human tissue. J Clin Invest 89: 2066-2070

10. Yamaguchi Y, Flier JS, Yokota A, Beneke H, Baker JM, Moller DE (1991) Functional properties of two naturally occurring isoforms of the human insulin receptor in Chinese hamster ovary cells. Endocrinology 129: 2058-2066

11. McClain DA (1991) Different ligand affinities of the two human insulin receptor splice variants are reflected in parallel changes in sensitivity for insulin action. Mol Endocrinol 5: 734-739

12. Vogt B, Carrascosa JM, Ermel B, Ullrich A, Haring $H$ (1991) The two isotypes of the human insulin receptor (HIR-A and HIR-B) follow different internalization kinetics. Biochem Biophys Res Commun 177: 1013-1018

13. Mosthaf L, Vogt B, Haring H, Ullrich A (1991) Altered expression of insulin receptor types $A$ and $B$ in the skeletal muscle of non-insulin-dependent diabetes mellitus. Proc Natl Acad Sci USA 88: 4728-4730

14. Kellerer M, Sesti G, Seffer E et al. (1993) Altered pattern of insulin receptor isotypes in skeletal muscle membranes of type 2 (non-insulin-dependent) diabetic subjects. Diabetologia 36: 628-632

15. Norgren S, Zierath J, Galuska D, Wallberg-Henriksson H, Luthman H (1993) Differences in the ratio of RNA encoding two isoforms of the insulin receptor between control and NIDDM patients. Diabetes 42: 675-681

16. Sesti G, Marini MA, Tullio AN et al. (1991) Altered expression of the two naturally occurring human insulin receptor variants in isolated adipocytes of non-insulin-dependent diabetes mellitus. Biochem Biophys Res Commun 181: $1419-1424$

17. Mosthaf L, Eriksson J, Haring H et al. (1993) Insulin receptor isotype expression correlates with risk of non-insulindependent diabetes. Proc Natl Acad Sci USA 90: 26332635

18. Hansen T, Bjørbaek C, Vestergaard H, Grønskov K, Bak JF, Pedersen O (1993) Expression of insulin receptor spliced variants and their functional correlates in muscle from patients with NIDDM. J Clin Endocrinol Metab 77: 1500-1505
19. Anderson CM, Henry RR, Knudson PE, Olefsky JM, Webster NJG (1993) Relative expression of insulin receptor isoforms does not differ in lean, obese, and NIDDM subjects. J Clin Endocrinol Metab 76: 1380-1382

20. DeFronzo RA, Tobin JD, Andres R (1979) Glucose clamp technique: a method for quantifying insulin secretion and resistance. Am J Physiol 237:E214-E223

21. Ebina Y, Ellis L, Jarnagin K et al. (1985) The human insulin receptor cDNA: the structural basis for hormone-activated transmembrane signalling. Science 40: 747-758

22. Sell SM, Reese D, Ossowski VM (1994) Insulin-inducible changes in insulin receptor $\mathrm{mRNA}$ splice variants. J Biol Chem 269: 30769-30772

23. Norgren S, Zierath J, Wedell A, Wallberg-Henriksson $\mathbf{H}$, Luthman H (1994) Regulation of human insulin receptor RNA splicing in vivo. Proc Natl Acad Sci USA 91: 14651469

24. Huang Z, Bodkin NL, Ortmeyer HK, Hansen BC, Shuldiner AR (1994) Hyperinsulinaemia is associated with altered insulin receptor mRNA splicing in muscle of the spontaneously obese diabetic rhesus monkey. J Clin Invest 94: $1289-1296$

25. Sbraccia P, D'Adamo M, Caiola S et al. (1994) The expression of the two insulin receptor isoforms is not altered in both skeletal muscle and liver of diabetic rats. Diabetes [Suppl 1] 43: 178A (Abstract)

26. Tamburrano G, Leonetti F, Sbraccia P, Giaccari A (1992) Total glucose uptake in hypoglycaemic syndromes. In: Andreani D, Lefebvre PJ, Marks V, Tamburrano G (eds) Recent advances on hypoglycaemia. Serono Symposia, vol 89. Raven Press, New York, pp 1-14

27. Leonetti F, Iozzo P, Giaccari A, Sbraccia P, Tamburrano G, Andreani D (1993) Absence of clinically overt atherosclerotic vascular disease and adverse changes in cardiovascular risk factors in 70 patients with insulinoma. $J$ Endocrinol Invest 16: 875-880

28. Nankervis A, Proietto J, Aitken P, Alford F (1985) Hyperinsulinaemia and insulin sensitivity: studies in subjects with insulinoma. Diabetologia 28: $427-431$

29. Bar RS, Gorden P, Roth J, Siebert C (1977) Insulin receptors in patients with insulinoma: changes in receptor affinity and concentrations. J Clin Endocrinol Metab 44: 12101213

30. Traedway JL, Whittaker J, Pessin JE (1989) Regulation of the insulin receptor kinase by hyperinsulinism. J Biol Chem 264: 15136-15143 